DOI: https://doi.org/10.47405/mjssh.v5i11.561

\begin{tabular}{|c|c|}
\hline 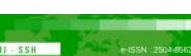 & Malaysian Journal of Social Sciences and Humanities (MJSSH) \\
\hline Malaysian Journal of & Volume 5, Issue 11, November 2020 \\
\hline (MJ-SSH) & e-ISSN : 2504-8562 \\
\hline & $\begin{array}{l}\text { Journal home page: } \\
\text { www.msocialsciences.com }\end{array}$ \\
\hline
\end{tabular}

\title{
Kepuasan Komunikasi Guru Sekolah Rendah: Satu Kajian Tinjauan di Bahagian Pedalaman Atas Sabah
}

\author{
Lily James Billy', Muhamad Suhaimi Taat ${ }^{1}$ \\ 1Fakulti Psikologi dan Pendidikan, Universiti Malaysia Sabah (UMS) \\ Correspondence: Lily James Billy (lilybilly74@yahoo.com)
}

\begin{abstract}
Abstrak
Kepuasan komunikasi merupakan jumlah kepuasan terhadap maklumat umum termasuk perubahan dalam polisi organisasi, prosedur, misi, visi, objektif, pencapaian, rancangan, struktur dan keadaan pekerjaan. Kajian ini bertujuan mengenal pasti kepuasan komunikasi dalam kalangan guru sekolah rendah di bahagian pedalaman atas negeri Sabah, Malaysia. Kajian berbentuk bukan jenis eksperimental ini menggunakan kaedah tinjauan dan mengabung tiga teknik pensampelan kebarangkalian dalam mendapatkan data. Data dikumpulkan menggunakan satu set soal selidik yang diadaptasi dari Downs dan Hazen (1977) dan ditadbir ke atas 458 orang responden guru. Data dianalisis menggunakan perisian IBM SPSS Statistics 25.0. Berdasarkan analisis deskriptif, variabel kepuasan komunikasi menunjukkan seramai 410 orang responden $(89.5 \%)$ berada pada tahap tinggi manakala 48 orang responden $(10.5 \%)$ berada pada tahap sederhana. Dapatan analisis Ujian-t yang diperoleh adalah tidak signifikan $(t=0.663$, $\mathrm{df}=456, \mathrm{p}>0.05$ ), yang menunjukkan tidak terdapat perbezaan kepuasan komunikasi berdasarkan jantina. Melalui ujian ANOVA sehala, kepuasan komunikasi berdasarkan pengalaman mengajar didapati tidak signifikan, $[\mathrm{F}(\mathrm{df}=2,455)=1.685, \mathrm{p}>0.05]$. Kajian menyimpulkan bahawa tiada perbezaan dalam kepuasan komunikasi berdasarkan pengalaman mengajar guru. Kajian mencadangkan agar kepuasan komunikasi guru berada pada tahap tinggi. Hal ini kerana kepuasan komunikasi guru adalah penting untuk memastikan kelancaran perkongsian kemahiran, ilmu, maklumat dan arahan serta mengelakkan konflik dan merupakan kunci kepada kejayaan serta keberhasilan di sekolah.
\end{abstract}

Kata kunci: kepuasan komunikasi, tahap, pengalaman mengajar

\section{Primary School Teachers' Communication Satisfaction: A Survey Research In Upper Interior Division In Sabah.}

\begin{abstract}
Communication satisfaction is the total satisfaction towards the information including the changes in the school policy, procedure, mission, vision, objective, achievement, plan, structure and work condition. This study was conducted to identify communication satisfaction among primary school teachers in upper interior division of Sabah. This non-experimental study used a survey method and combined three probability sampling techniques in obtaining samples. Data were collected using a set of adapted questionnaires from the Downs and Hazen Questionnaires (1977) and administered to 458 teachers. The data were analyzed using the IBM SPSS Statistics 25.0. Based on descriptive analysis, communication satisfaction was at high level. The result of the $t$ - test showed insignificant finding $(t=0.663, d f=456$,
\end{abstract}


$\mathrm{p}>0.05)$, which indicated there was no difference in communication satisfaction based on gender. Through a one- way ANOVA test, communication satisfaction based on teaching experience was also found to be insignificant $[\mathrm{F}(\mathrm{df}=2,455)=1.685, \mathrm{p}>0.05]$. This research concluded there was no difference in communication satisfaction based on teaching experience. This study suggests the teachers to have high level of communication satisfaction as it is important to ensure the flows of skills sharing, knowledge, information, instruction and to avoid conflict and is the key to success and achievement in school.

Keywords: communication satisfaction, level, teaching experience

\section{Pengenalan}

Kepuasan komunikasi merupakan kunci kepada kejayaan sesebuah organisasi (Al-Nashmi \& Hj. Syd Zin, 2011). Kepuasan komunikasi membantu ahli mengetahui keadaan dalam organisasi dan mengadakan hubungan yang baik dengan semua ahli dalam organisasi seterusnya mengurangkan tekanan dalam pekerjaaan (Salami, Ojokuku, \& Ilesanmi, 2010).

Kejayaan sesebuah organisasi bergantung kepada keberkesanan sistem komunikasi dan kepuasan komunikasi antara ahli (Wagner, Bezuidenhout \& Roos, 2015). Sorotan literatur menyatakan tahap kepuasan komunikasi yang tinggi meningkatkan prestasi kerja ahli dalam organisasi (Rajesh \& Suganthi, 2014).

Isu yang timbul dalam kepuasan komunikasi pada hari ini ialah kebanyakan masalah di sekolah timbul berkaitan dengan kegagalan dalam merancang dan mengurus komunikasi dalaman antara kumpulan kerja yang membawa kepada kesan yang membinasakan (Windy Anjilus, 2019). Ketidakpuasan komunikasi boleh berlaku sekiranya guru- guru tidak memahami sesuatu mesej dengan jelas yang akhirnya mengundang kepada buruk sangka dan salah sangka sesama guru- guru (Ab. Aziz Yusuf, 2003; Ahmad, Jamilah \& Boon, Yusof, 2011).

Dalam kajian ini, kepuasan komunikasi didefinisikan sebagai kepuasan guru-guru terhadap tujuh aspek dalam komunikasi iaitu meliputi i) iklim komunikasi, 2) integrasi organisasi, 3) media kualiti, 4) komunikasi dengan pentadbir,5) komunikasi mendatar atau tidak formal, 6) perspektif organisasi dan 7) maklum balas peribadi.

\section{Objektif Kajian}
i Mengukur tahap kepuasan komunikasi.
ii Mengenal pasti perbezaan skor min kepuasan komunikasi berdasarkan jantina.
iii Mengenal pasti perbezaan skor min kepuasan komunikasi berdasarkan pengalaman mengajar.

\section{Hipotesis Kajian}

Ho1: Tidak terdapat perbezaan skor min yang signifikan kepuasan komunikasi berdasarkan jantina.

Ho2: Tidak terdapat perbezaan skor min yang signifikan kepuasan komunikasi berdasarkan pengalaman mengajar.

\section{Sorotan Literatur}

Kepuasan komunikasi didefinisikan sebagai kepuasan yang diperolehi oleh ahli dalam komunikasi dalam sesebuah organisasi (Miti'c, Nikoli'c, Jankov, Vukonjanski \& Terek, 2017). Seven (2012) mendefinisikan kepuasan komunikasi sebagai jumlah kepuasan terhadap maklumat umum termasuk 
perubahan dalam polisi organisasi, prosedur, misi, visi, objektif, pencapaian, rancangan, struktur dan keadaan pekerjaan.

Kajian ini menggunakan Model Kepuasan Komunikasi Downs dan Adrian (2004). Dalam kajian ini kepuasan komunikasi didefinisikan sebagai kepuasan di dalam tujuh aspek komunikasi iaitu kepuasan dari segi iklim komunikasi, komunikasi dengan pentadbir, integrasi organisasi, kualiti media, komunikasi horizontal, perspektif organisasi dan maklum balas peribadi. Iklim komunikasi merujuk kepada tahap komunikasi guru dalam sekolah. Iklim komunikasi menerangkan sejauh manakah komunikasi dalam sekolah memberi motivasi dan rangsangan terhadap guru untuk berusaha mencapai matlamat yang telah ditetapkan dalam sekolah. Komunikasi dengan guru besar meliputi sejauh manakah guru besar bersikap terbuka terhadap sesuatu idea, tahap guru besar mendengar dan memberi perhatian.

Integrasi organisasi merupakan tahap guru menerima maklumat tentang persekitaran langsung sekolah berkaitan tahap kepuasan maklumat diterima berkenaan rancangan sekolah dan maklumat tentang guru dalam sekolah. Kualiti media merujuk kepada kualiti mesyuarat di sekolah meliputi sama ada mesyuarat dirancang dengan baik, penggunaan arahan bertulis yang jelas dan ringkas dan juga sama ada tahap komunikasi semasa mesyuarat adalah memuaskan. Komunikasi tidak formal dan mendatar merujuk kepada sama ada ia diamalkan secara tepat dan bebas. Perspektif organisasi meliputi maklumat berkenaan sekolah secara keseluruhan termasuklah perubahan, kedudukan kewangan dan objektif. Maklum balas peribadi merujuk sama ada guru merasakan kriteria mereka dinilai adalah adil. Rajah 1 menunjukkan Model Kepuasan Komunikasi Downs dan Adrian (2004) yang dijadikan landasan bagi memahami konsep kepuasan komunikasi.

\section{Metod Kajian}

Penyelidikan ini berbentuk jenis bukan eksperimental menggunakan kaedah tinjauan sampel. Kajian ini mengaplikasikan pendekatan kuantitatif bagi memudahkan perolehan data, di samping memastikan kebolehpercayaan dan kesahannya. Populasi kajian merupakan guru sekolah rendah harian biasa kerajaan di pedalaman atas negeri Sabah seramai 2686 orang. Berlandaskan saranan Krejcie dan Morgan (1970), sebanyak 458 set borang soal selidik telah diedarkan dan diproses. Bagi tujuan mendapatkan sampel, gabungan pensampelan berstrata, kluster dan rawak mudah telah diaplikasikan dalam kajian ini.

Variabel kepuasan komunikasi guru diukur menggunakan Soal Selidik Kepuasan Komunikasi yang dibangun oleh Downs dan Hazen (1977). Kebenaran untuk mengadaptasi soal selidik agar bersesuaian dengan konteks kajian telah diperoleh daripada pemilik asal. Soal selidik telah menjalani proses ' $b a c k$ to back translation' bertujuan memelihara maksud sebenar soal selidik.

Kajian rintis dilaksanakan bagi menguji kesahan konstruk serta kebolehpercayaan alat kajian. Kesahan konstruk soal selidik telah dilaksanakan menggunakan analisis faktor penerokaan (Exploratory Factor Analysis). Walau bagaimanapun sebelum itu, ujian untuk menentukan kesempurnaan atau kecukupan item dijalankan terlebih dahulu. Pallant (2013) menjelaskan dua pengukuran statistik yang berupaya menentukan kesesuaian menjalankan faktor analisis adalah sukatan kecukupan pensampelan KaiserMeyer-Olkin (Kaiser-Meyer-Olkin measure of sampling adequacy) dan juga ujian kesferaan Bartlett (Bartlett's test of sphericity). Ujian Kaiser-Meyer-Olkin (KMO) bertujuan menentukan kesempurnaan atau kecukupan item atau sampel soalan bagi menentukan sama ada data berkenaan sesuai dijalankan analisis faktor atau tidak. Ghazali et al. (2016) menegaskan penentuan aras diterima ialah nilai $>.600$, $\operatorname{sig}=\mathrm{p}<.000$. Menurut Lay, Khoo dan Ley (2016) nilai ujian kesferaan Bartlett yang besar serta signifikan penting bagi membolehkan analisis faktor dilaksanakan. Pallant (2013) berpendapat Ujian Bartlett's Test of Sphericity berupaya mengenal pasti sama ada korelasi item memadai bagi melakukan analisis faktor dengan nilai signifikan pada $\mathrm{p}<.05$.

Bagi tujuan kesahan, sebanyak 35 item variabel kepuasan komunikasi meliputi tujuh konstruk iaitu iklim komunikasi, komunikasi dengan pentadbir, integrasi organisasi, kualiti media, komunikasi tidak formal, perspektif organisasi dan maklum balas peribadi dimuatkan untuk dianalisis. Keputusan ujian kesferaan Bartlett didapati besar dan signifikan $\left(\mathrm{x}^{2}=2522.235, \mathrm{df}=595, \mathrm{p}<0.05\right)$, manakala, nilai ujian sukatan 
kecukupan pensampelan Kaiser-Meyer-Olkin ialah 0.81, jauh lebih tinggi daripada nilai 0.60 yang disarankan. Oleh itu, sifat kebolehfaktoran dapat diandaikan dan ujian kebolehpercayaan boleh dijalankan. Keputusan ujian kebolehpercayaan menunjukkan nilai pekali Alpha Cronbach variabel kepuasan komunikasi ialah 0.92. Hal ini memberikan petanda bahawa kebolehpercayaan item konstruk kajian adalah tinggi dan sesuai berpandukan saranan Fraenkel dan Wallen (1996) dan Mohd. Majid (2000). Setelah analisis faktor dijalankan terdapat satu item yang mempunyai nilai muatan kurang daripada 0.40. Manakala empat item mempunyai cross loading. Justeru lima item bermasalah telah digugurkan. Jumlah item sebenar bagi kajian ini ialah 30 item dengan tujuh konstruk.

\section{Hasil Kajian}

Analisis deskriptif yang dijalankan menunjukkan skor min kepuasan komunikasi ( $\mathrm{M}=3.900, \mathrm{SP}=0.169)$ berada pada tahap tinggi berlandaskan saranan Levin dan Rubin (1998) serta Mohd Yusof Abdullah (2006). Skor min berdasarkan konstruk juga dipersepsikan tinggi dengan nilai melebihi 3.67. Konstruk yang memperoleh skor min tertinggi ialah konstruk integrasi organisasi $(\mathrm{M}=4.081, \mathrm{SP}=0.320)$. Manakala, konstruk yang mendapat skor min terendah ialah iklim komunikasi $(\mathrm{M}=3.734, \mathrm{SP}=0.314)$. Rujuk Jadual 1.

Jadual 1: Skor Min Variabel dan Konstruk Kajian

\begin{tabular}{lccc}
\hline \multicolumn{1}{c}{ Variabel/ Konstruk } & N & Min & SP \\
\hline Kepuasan Komunikasi & $\mathbf{4 5 8}$ & $\mathbf{3 . 9 0 0}$ & $\mathbf{0 . 1 6 9}$ \\
Iklim Komunikasi & & 3.734 & 0.314 \\
Komunikasi dengan Pentadbir & & 3.929 & 0.329 \\
Integrasi Organisasi & & 4.081 & 0.320 \\
Kualiti Media & & 4.025 & 0.330 \\
Komunikasi Tidak Formal & & 3.893 & 0.293 \\
Perspektif Organisasi & & 3.859 & 0.298 \\
Maklum Balas Peribadi & & 3.812 & 0.385 \\
\hline
\end{tabular}

\section{Tahap kepuasan Komunikasidi Bahagian Pedalaman Atas Sabah}

Bagi menentukan tahap kepuasan komunikasi, analisis deskriptif iaitu kekerapan, peratusan dan min digunakan. Tahap pemeringkatan dilaporkan sama ada tinggi, sederhana atau rendah. Dapatan analisis pemeringkatan tahap dalam Jadual 2 menunjukkan kepuasan komunikasi berada pada tahap sederhana dan tinggi. Hasil pemerhatian terhadap bilangan serta peratusan membuktikan bahawa tahap kepuasan komunikasi berada tahap tinggi (89.5\%). Hanya sebilangan kecil dalam kalangan guru sekolah rendah mempunyai tahap kepuasan komunikasi yang sederhana $(10.5 \%)$.

Jadual 2: Tahap Pemeringkatan Angkubah Kajian

\begin{tabular}{ccccc}
\hline \multirow{2}{*}{ Variabel } & \multicolumn{3}{c}{ Tahap } & \multirow{2}{*}{ Jumlah } \\
\cline { 2 - 4 } & $\begin{array}{c}\text { Rendah } \\
\mathbf{N}(\%)\end{array}$ & $\begin{array}{c}\text { Sederhana } \\
\mathbf{N}(\%)\end{array}$ & $\begin{array}{c}\text { Tinggi } \\
\mathbf{N}(\boldsymbol{\%})\end{array}$ & \\
\hline Kepuasan Komunikasi & - & $48(10.5 \%)$ & $410(89.5 \%)$ & 458 \\
\hline
\end{tabular}

\section{Perbezaan Skor Min Kepuasan Komunikasi Berdasarkan Jantina}

Hipotesis Nul 1 (Ho1) : Tidak terdapat perbezaan skor min yang signifikan kepuasan komunikasi guru berdasarkan jantina.

Analisis bagi sampel kajian ini $(\mathrm{N}=458)$ menunjukkan terdapat perbezaan skor min yang kecil sebanyak $\mathrm{M}=0.011$ antara kedua- dua kumpulan responden berhubung pengamalan kepuasan komunikasi. Analisis menunjukkan skor min lelaki $(\mathrm{M}=3.907, \mathrm{SP}=0.164, \mathrm{~N}=170)$ lebih tinggi berbanding skor 
min perempuan $(\mathrm{M}=3.896, \mathrm{SP}=0.173, \mathrm{~N}=288)$. Nilai min yang lebih tinggi bagi kumpulan responden lelaki menunjukkan mereka mempunyai tahap kepuasan komunikasi yang lebih tinggi berbanding kumpulan responden perempuan. Berlandaskan hasil ujian-t, keputusan yang telah diperoleh adalah tidak signifikan $(\mathrm{t}=0.663, \mathrm{df}=456, \mathrm{p}>0.05) \mathrm{Hal}$ ini bermakna Hipotesis Nul 1 (Ho1) gagal ditolak. Justeru dapatan ini menunjukkan bahawa tidak terdapat perbezaan tahap kepuasan komunikasi antara guru lelaki dan perempuan (Jadual 3).

Jadual 3: Analisis Ujian -t Kepuasan Komunikasi Berdasarkan Jantina

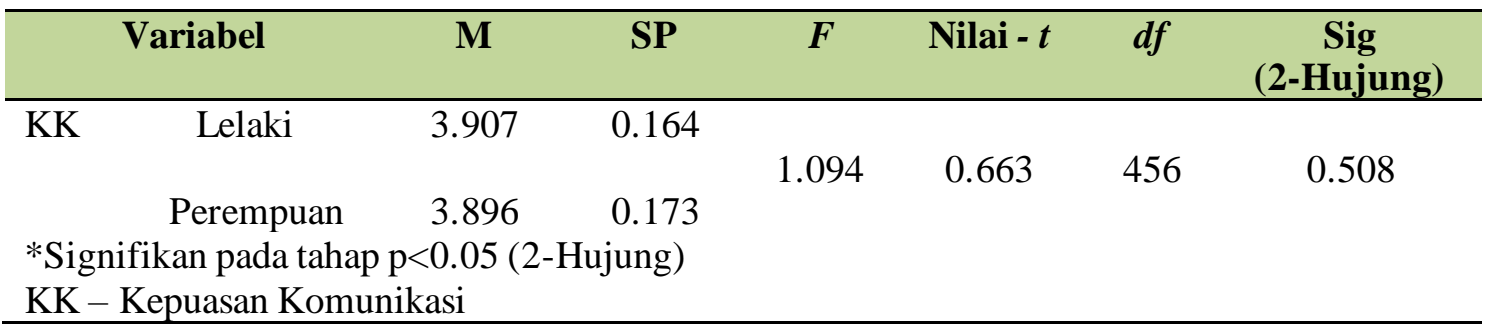

\section{Perbezaan Skor Min Kepuasan Komunikasi Berdasarkan Pengalaman Mengajar}

Hipotesis Nul 2 (Ho2): Tidak terdapat perbezaan skor min yang signifikan kepuasan komunikasi berdasarkan pengalaman mengajar.

Berpandukan analisis deskriptif perbezaan skor min kepuasan komunikasi berdasarkan pengalaman mengajar seperti ditunjukkan dalam Jadual 4, daripada jumlah sampel kajian ( $\mathrm{N}=458$ ), didapati skor min guru yang mempunyai pengalaman mengajar lebih 20 tahun adalah lebih tinggi ( $M=3.910, S P=0.160$, $\mathrm{N}=158)$ berbanding kumpulan guru dengan pengalaman mengajar kurang 10 tahun $(\mathrm{M}=3.875$, $\mathrm{SP}=0.169, \mathrm{~N}=113)$ dan pengalaman mengajar antara $10-20$ tahun $(\mathrm{M}=3.907, \mathrm{SP}=0.177, \mathrm{~N}=187)$. Perbezaan skor min menunjukkan kumpulan responden lebih 20 tahun pengalaman mengajar mengalami kepuasan komunikasi yang lebih tinggi berbanding dengan dua kumpulan responden lain.

Jadual 4: Analisis Deskriptif Kepuasan Komunikasi Berdasarkan Pengalaman Mengajar

\begin{tabular}{llccc}
\hline Variabel & & N & M & SP \\
\hline Kepuasan & Kurang 10 tahun & 113 & 3.875 & 0.169 \\
Komunikasi & 10 - 20 Tahun & 187 & 3.907 & 0.177 \\
& Lebih 20 tahun & 158 & 3.910 & 0.160 \\
& Jumlah Keseluruhan & 458 & 3.900 & 0.169 \\
\hline
\end{tabular}

Keputusan analisis ANOVA Sehala seperti dalam Jadual 5 menunjukkan perbandingan skor min kepuasan komunikasi berdasarkan pengalaman mengajar. Berdasarkan nilai statistik diperoleh, kepuasan komunikasi berdasarkan pengalaman mengajar didapati tidak signifikan, $[\mathrm{F}(\mathrm{df}=2,455)=$ $1.685, \mathrm{p}>0.05]$. Dapatan analisis ini menunjukkan bahawa tidak terdapat perbezaan dalam kepuasan komunikasi berdasarkan pengalaman mengajar.

Jadual 5: Analisis ANOVA Sehala Kepuasan Komunikasi Berdasarkan Pengalaman Mengajar

\begin{tabular}{llccccc}
\hline Variabel & & Ss & $\boldsymbol{d f}$ & $\boldsymbol{M S}$ & $\boldsymbol{F}$ & Sig \\
\hline Kecerdasan Emosi & Antara Kumpulan & 0.097 & 2 & 0.048 & 1.685 & 0.187 \\
& Dalam Kumpulan & 13.031 & 455 & 0.029 & & \\
& Jumlah & 13.128 & 457 & & & \\
Keseluruhan & & & & & \\
\hline
\end{tabular}

*Signifikan pada tahap $\mathrm{p}<0.05$ (2-Hujung) 


\section{Perbincangan Kajian}

Dapatan kajian ini menunjukkan skor min angkubah kepuasan komunikasi berada pada tahap tinggi secara keseluruhannya. Hal ini bermakna kesemua konstruk variabel kepuasan komunikasi yang terdiri daripada iklim komunikasi, komunikasi dengan pentadbir, integrasi organisasi, kualiti media, komunikasi tidak formal, perspektif organisasi dan maklum balas peribadi berada pada tahap tinggi.

Dapatan kajian ini serupa dengan dapatan kajian oleh Vermeir, Blot, Degroote, Vandijck, Mariman, Vanacker dan Vogelaers (2018) dalam kajian mereka melaporkan 303 orang responden mempunyai tahap kepuasan komunikasi yang tinggi. Dapatan kajian ini juga selari dengan dapatan kajian oleh Park dan Raile (2010) dan Varona (1991). Alanezi (2011) juga melaporkan dapatan kajian yang serupa. Beliau telah menjalankan kajiannya terhadap 465 orang responden yang terdiri dari kalangan guru sekolah menengah di negara Kuwait yang melaporkan majoriti responden mempunyai tahap kepuasan komunikasi yang tinggi.

Dapatan analisis menunjukkan terdapat perbezaan skor min yang kecil antara kedua- dua kumpulan responden berhubung pengamalan kepuasan komunikasi. Analisis menunjukkan skor min responden lelaki lebih tinggi berbanding skor min responden perempuan. Nilai min yang lebih tinggi bagi kumpulan responden lelaki menunjukkan guru- guru lelaki di pedalaman atas negeri Sabah mempunyai persepsi yang lebih tinggi terhadap kepuasan komunikasi berbanding guru- guru perempuan. Dapatan kajian ini disokong oleh dapatan kajian Alanezi (2011) yang mendapati terdapat perbezaan yang agak kecil antara kedua- dua kumpulan responden guru di Kuwait. Dalam dapatan kajiannya, beliau juga melaporkan responden guru lelaki mempunyai persepsi yang lebih tinggi terhadap kepuasan komunikasi berbanding guru perempuan.

Berlandaskan hasil ujian-t, keputusan yang diperoleh adalah tidak signifikan. Hal ini bermakna tiada perbezaan kepuasan komunikasi antara responden guru lelaki dan responden guru perempuan dalam kajian ini. Dalam perkataan lain, persepsi guru lelaki dan perempuan di pedalaman atas negeri Sabah terhadap variabel kepuasan komunikasi adalah sama sahaja. Dapatan kajian ini sealiran dan disokong oleh dapatan kajian Alanezi (2011) yang menunjukkan tiada perbezaan yang signifikan antara responden guru lelaki dan perempuan terhadap variabel kepuasan komunikasi di negara Kuwait.

Berpandukan analisis deskriptif perbezaan skor min kepuasan komunikasi berdasarkan pengalaman mengajar didapati skor min guru yang mempunyai pengalaman mengajar lebih 20 tahun (sangat berpengalaman) adalah lebih tinggi berbanding kumpulan guru dengan pengalaman mengajar kurang 10 tahun (kurang pengalaman) dan pengalaman mengajar antara 10 - 20 tahun (berpengalaman). Perbezaan skor min menunjukkan kumpulan responden lebih 20 tahun pengalaman mengajar mengalami kepuasan komunikasi yang lebih tinggi berbanding dengan dua kumpulan responden lain.

Berdasarkan nilai statistik diperoleh daripada analisis ANOVA sehala, kepuasan komunikasi berdasarkan pengalaman mengajar didapati tidak signifikan. Dapatan analisis ini menunjukkan bahawa tidak terdapat perbezaan dalam kepuasan komunikasi berdasarkan pengalaman mengajar. Dalam perkataan lain, pengalaman mengajar guru tidak memberi kesan terhadap persepsi guru dalam kepuasan komunikasi.

Dapatan kajian ini sealiran dengan dapatan kajian Varona (1991) dalam kajiannya terhadap responden di Guatemala. Perolehan dapatan kajian yang serupa juga dilaporkan oleh Alanezi (2011). Kajian yang dijalankan oleh Seven (2012) juga menunjukkan dapatan yang serupa dengan dapatan kajian ini iaitu tidak terdapat hubungan yang signifikan kepuasan komunikasi berdasarkan pengalaman bekerja. Hal ini bermakna tempoh pengalaman bekerja ahli tidak mendatangkan kesan terhadap kepuasan komunikasi ahli.

Guru- guru kurang pengalaman, berpengalaman dan sangat berpengalaman di pedalaman atas negeri Sabah mempunyai persepsi yang sama sahaja terhadap kepuasan komunikasi. Guru- guru dari tiga kumpulan pengalaman mengajar mempersepsikan kesemua aspek kepuasan komunikasi iaitu iklim 
komunikasi, komunikasi dengan pentadbir, integrasi organisasi, kualiti media, komunikasi tidak formal, perspektif organisasi dan maklum balas peribadi sama sahaja.

Berpandukan dapatan dalam penyelidikan ini, beberapa cadangan diutarakan untuk kajian lanjutan. Kajian tentang kepuasan komunikasi pada masa akan datang boleh dikaji berkaitan hubungannya dengan aktiviti pengajaran dan pembelajaran, gaya kepimpinan persekitaran, kepimpinan distributif, kecerdasan spiritual dan intelektual guru. Selain itu, boleh dimasukkan variabel pengantara untuk melihat hubungan variabel tidak bersandar dan variabel bersandar. Kajian juga boleh dijalankan di institusi pengajian lain.

\section{Kesimpulan}

Kepuasan komunikasi dalam kalangan warga pendidik penting diamalkan pada tahap tinggi. Hal ini disebabkan kebanyakan masalah di sekolah timbul disebabkan kegagalan dalam merancang dan mengurus komunikasi dalaman dalam kalangan guru yang akhirnya membawa kepada kesan yang memudaratkan.

\section{Rujukan}

Ab. Aziz Yusuf. (2003). Gelagat Organisasi : Teori, Isu dan Aplikasi. Prentice Hall Pearson Malaysia Sdn. Bhd. Petaling Jaya, Selangor.

Ahmad, Jamilah and Boon, Yusof.(2011). Amalan kepimpinan sekolah berprestasi tinggi (SBT) di Malaysia. journal of edupress, 1,323-335.

Alanezi, A. S. (2011). Communication satisfaction and its relationship to organizational commitment among secondary school teachers in Kuwait. (Unpublished doctoral dissertation). Indiana State University, Indiana.

Al-Nashmi, M. M., \& Syd Zin, H. S. A. R. (2011). Variation in Communication Satisfaction of Academic Staff in Universities in Yemen Depending on National Culture. Cross Cultural Management: An International Journal, 18 (1), 87-105.

Downs, C. W., \& Hazen, M. D. (1977). A Factor Analytic Study of Communication Satisfaction. The Journal of Business Communication (1973), 14(3), 63-73.

Downs, C. W., \& Adrian, A. D. (2004). Assessing Organizational Communication: Strategic Communication Audits. New York, NY: The Guilford Press.

Fraenkel, J. R., \& Wallen, N. E. (1996). How to Design and Evaluate Research in Education. $6^{\text {th }}$ ed. New York. McGraw- Hill.

Ghazali Darusalam dan Sufean Hussin. (2016). Metodologi Penyelidikan dalam Pendidikan. Amalan dan Analisis Kajian. Kuala Lumpur: Universiti Malaya.

Krejcie, R. V., \& Morgan, D. W. (1970). Determining Sample Size for Research Activities. Educational and Psychological Measurement, 30(3), 607-610.

Lay, Y. F., Khoo, C. H., \& Ley, C. M. (2016). Pengenalan Kepada Analisis Data Dengan IBM SPSS STATISTICS 19 Dalam Penyelidikan Sains Sosial. Kota Kinabalu: Penerbit Universiti Malaysia Sabah.

Levin, R. I., \& Rubin, D. S. (1998). Statistics for Management. Upper Saddle River, NJ: Prentice Hall.

Mitić, S., Nikolić, M., Jankov, J., Vukonjanski, J., \& Terek, E. (2017). The impact of information technologies on communication satisfaction and organizational learning in companies in Serbia. Computers in Human Behavior, 76, 87-101.

Mohd. Majid Konting. (2000). Kaedah Penyelidikan Pendidikan. Kuala Lumpur: Dewan Bahasa dan Pustaka.

Mohd Yusof Abdullah. (2006). Pengaruh Motif, Sikap dan Latihan Perguruan Terhadap Profesionalisme Keguruan di kalangan Pelajar Program Pendidikan IPTA. Tesis Doktor Falsafah. Kota Kinabalu: Universiti Malaysia Sabah.

Pallant, J. (2013). SPSS Survival Manual: A Step by Step Guide to Data Analysis Using IBM SPSS (5 ${ }^{\text {th }}$ e.) England: Mc Graw-Hill. 
Park, H. S., \& Raile, A. N. (2010). Perspective Taking and Communication Satisfaction in Coworker Dyads. Journal of Business and Psychology, 25(4), 569-581.

Rajesh, J. I., \& Suganthi, L. (2014). The Relationship Between Transformational Leadership and Followers' Interpersonal Communication Satisfaction in Indian Organisations. International Journal of Business Excellence, 7(1), 28-51.

Salami, A. O., Ojokuku, R. M., \& Ilesanmi, O. A. (2010). Impact of Job stress on managers' performance. European Journal of Scientific Research, 45(2), 249-260.

Seven, H. (2012). An Analysis Of The Internal Communication Satisfaction On Organizational Commitment In The Turkish National Police (TNP). Postgraduate Dissertation. University of Baltimore, Maryland, USA.

Varona, F. (1991). Communication satisfaction and organizational commitment: A study in three Guatemalan organizations (Doctoral dissertation, University of Kansas).

Vermeir, P., Blot, S., Degroote, S., Vandijck, D., Mariman, A., Vanacker, T., \& Vogelaers, D. (2018). Communication Satisfaction and Job Satisfaction Among Critical Care Nurses and Their Impact on Burnout and Intention to Leave: A Questionnaire Study. Intensive and Critical Care Nursing, $48,21-27$.

Wagner, J. D., Bezuidenhout, M. C., \& Roos, J. H. (2015). Communication Satisfaction of Professional Nurses Working in Public Hospitals. Journal of Nursing Management, 23(8), 974-982.

Windy Anjilus. (2019). Pengaruh gaya Kepemimpinan Transformasi, Iklim dan Budaya Sekolah Terhadap Kepuasan Kerja Guru akademik di Sabah. Tesis Doktor Falsafah. Kota Kinabalu, Sabah: Universiti Malaysia Sabah. 